\section{Pediatría y cultura de viaje: los pensionados españoles y la apropiación del laboratorio en la periferia, 1907-1939}

\section{Pediatrics and travel culture: Spanish travel award-holders and the appropriation of laboratories on the periphery, 1907-1939}

\author{
Raúl Velasco Morgado \\ Profesor asociado, Faculdad de Medicina/ \\ Universidad de Salamanca. \\ Salamanca - España \\ orcid.org/0000-0002-6958-9090 \\ raulvmorgado@hotmail.com
}

Recebido em 23 jul. 2017.

Aprovado em 6 mar. 2018.

http://dx.doi.org/10.1590/\$0104-59702019000300007
VELASCO MORGADO, Raúl. Pediatría y cultura de viaje: los pensionados españoles y la apropiación del laboratorio en la periferia, 1907-1939. História, Ciências, Saúde - Manguinhos, Rio de Janeiro, v.26, n.3, jul.-set. 2019, p.841-862.

\section{Resumen}

Partiendo de la hipótesis de que el laboratorio jugó un papel importante en la autonomía disciplinar de la pediatría, este artículo estudia la influencia del viaje científico en la apropiación de nuevas metodologías por parte de los pediatras y puericultores españoles del primer tercio del siglo XX. Para ello, se analizan las pensiones concedidas a tal efecto por la Junta para Ampliación de Estudios e Investigaciones Científicas. Se describe la geografía científica creada por el programa y se profundiza en el papel de los mentores - especialmente de Gustavo Pittaluga (1876-1956) - en este proceso. Además de un estudio prosopográfico del grupo, se presentan tres casos que demuestran la importancia del programa en el encuentro de la pediatría con la bacteriología, la anatomía patológica y la bioquímica.

Palabras clave: pediatría; siglo XX; Junta para Ampliación de Estudios; laboratorio; Gustavo Pittaluga (1876-1956).

\section{Abstract}

Starting from the hypothesis that laboratories played an important role in pediatrics becoming an autonomous discipline, this article studies the influence of scientific travel on the appropriation of new methodologies by Spanish pediatricians and child-care experts in the first third of the twentieth century. To do so, it analyzes the travel awards granted by the Junta para Ampliación de Estudios e Investigaciones Cientificas. It describes the scientific geography created by the program and takes an in-depth look at the role of mentors - especially Gustavo Pittaluga (1876-1956) - in this process. In addition to a prosopographical study of the group, it presents three cases that demonstrate the importance of the program in bringing pediatrics into contact with bacteriology, pathological anatomy and biochemistry.

Keywords: pediatrics; twentieth century; Junta para Ampliación de Estudios; laboratory; Gustavo Pittaluga (1876-1956). 


\section{Cultura de viaje y cultura de laboratorio}

El primer tercio del siglo XX resultó definitivo para la concreción de la autonomía de la pediatría como disciplina (Seidler, 1974). Los cambios de la ciencia médica en general y del modelo asistencial - fundamentalmente una fuerte tecnologización, una aceleración de la especialización y la consolidación de un modelo hospitalocéntrico - forzaron a la especialidad a tomar unos derroteros concretos para adaptarse a los nuevos espacios y crear una identidad propia.

La pediatría se enfrentó al reto de afianzar su posición, tanto en las facultades de medicina como en los hospitales y los recursos de laboratorio parecían otorgarle ciertas ventajas en este proceso. En la universidad, unas tecnologías de laboratorio propias le ofrecían una capacidad investigadora diferenciadora que se concretaba en un aumento de autoridad académica. En el ámbito asistencial, ante la ausencia total de hospitales monográficos en España, la especialidad se vio obligada a crecer en grandes centros hospitalarios generalistas; en este contexto, el dominio de ciertas técnicas de laboratorio les otorgaba una marcada independencia respecto a los servicios "de adultos". El laboratorio se convirtió, pues, en un espacio de poder académico y de autoridad científica y médica. Contar con una infraestructura propia dentro de los mismos servicios de pediatría fue clave en este sentido.

El laboratorio se estaba constituyendo paulatinamente en un escenario físico indispensable para la producción del conocimiento médico y, de una forma más lenta, pero transformadora, para la asistencia clínica. La instauración de lo que Ackerknecht (1967) denominó "medicina de laboratorio" ha venido ocupando las agendas de los historiadores de la ciencia durante décadas. Al conceptualizarla, López Piñero le dotó de cierta estabilidad historiográfica en su escuela (López Piñero, 1974, 1985). No obstante, el tema merece revisiones en profundidad. En un artículo reciente, Steve Sturdy (2011) ha puesto de manifiesto que la relación entre la "ciencia de laboratorio" y la "medicina clínica" se ha venido presentado durante los últimas dos décadas por parte de la historiografía médica en términos de divergencia, tensión y conflicto. En el mismo trabajo, propone redirigir el enfoque y presentar ambas como complementarias, algo que se ha de validar en diferentes contextos nacionales y disciplinares.

El objetivo principal de este artículo será abordar esta interacción para el caso de la pediatría en España y ponderar la importancia del viaje científico en este proceso. Como parte de la "periferia" de Europa, la comunidad pediátrica española se vio obligada a utilizar una serie de estrategias para ponerse en contacto con las tendencias internacionales y llevar a cabo su apropiación. ${ }^{1}$ Entre éstas destacó, por su poder transformador, el viaje científico. Aunque heredero del espíritu ilustrado en el mundo contemporáneo, el viaje científico se tuvo que amoldar - y a su vez contribuir - al nuevo marco de profesionalización y especialización de la ciencia (Simões, Carneiro, Diogo, 2003). Para el caso de los conocimientos de laboratorio - básicamente instrumentales y de procedimientos - el viaje se convirtió en una herramienta esencial. Completaba de una manera irremplazable los conocimientos transmitidos a través de correspondencia, artículos, manuales o incluso lo comunicado personalmente en congresos científicos. 
Los trabajos dedicados a los viajes de los pediatras de los países de la periferia y el papel que jugaron estos en la apropiación de las tecnologías de laboratorio son muy escasos. Sin embargo, el trabajo de Weaver (2013) para la escuela de Glasgow es muy elocuente al respecto: la estancia de Leonard Findlay (1878-1947) con Otto Heubner (1843-1926) y Heinrich Finkelstein (1865-1942) en Berlín fue determinante para, a su regreso, erigir un nuevo departamento donde las ciencias de laboratorio se desarrollaron en íntima relación con la pediatría más clínica (Weaver, 2013).

Si se aborda el problema del viaje científico en la España del siglo XX, resulta imposible no referirse al programa de pensiones del primer organismo oficial de ciencia del país: la Junta para Ampliación de Estudios e Investigaciones Científicas (JAE). Antes de su fundación - como ocurría con el resto de las disciplinas científicas - los antecedentes de viajes habían sido muy escasos para la pediatría española. La movilidad de los científicos y médicos del país era, en general, muy pobre. Las estancias en el extranjero eran una excepción reservada a los pocos que se podían permitir un desembolso pecuniario personal y esto hacía que, al no contar con la supervisión de un mecenas cualificado, no se asegurara ningún tipo de calidad. A pesar de todos estos impedimentos, varios factores como la eficacia del viaje como complemento a la nula formación oficial de la especialidad, las experiencias de personajes de gran autoridad - como Andrés Martínez Vargas (1861-1948) - y lo preciado de contar con estos antecedentes en las oposiciones a la cátedra, habían creado, a comienzos del siglo $\mathrm{XX}$, una cierta "cultura de viaje" entre las élites de la disciplina.

Los movimientos regeneracionistas terminaron influyendo en las primeras políticas científicas del país y ya en 1900 se ensayó un primitivo sistema de concesión de pensiones por parte del Ministerio de Instrucción Pública. Su impacto, sin embargo, fue escaso: apenas dos médicos - uno de ellos, el pediatra Enrique Suñer Ordóñez (1878-1941) - pudieron aprovechar el programa (Baratas Díaz, Fernández Pérez, 1993). Aquellos más que tímidos inicios se convirtieron en un aluvión de pensionados en el extranjero gracias a la instauración de la JAE, que se convirtió en un verdadero proyecto europeizador. El gran número de ayudas, la selección personal de los pensionados, el control de la actividad de estos mediante la exigencia de memorias y la promoción de sus carreras a su vuelta a España, marcaron la diferencia con los intentos anteriores (Sánchez Ron, 1987; Sánchez Ron, García Velasco, 2010).

La influencia del programa de la JAE sobre las ciencias médicas básicas ha sido ampliamente estudiado (Barona, 1990; Baratas Díaz, Fernández Pérez, 1993; Baratas Díaz, 1997; Álvarez Peláez, 2007; Baratas Díaz, 2007; Velasco Morgado, 2010); por el contrario, cuáles fueron sus consecuencias sobre las ciencias clínicas es un tema poco trabajado hasta el momento. Aparte de la psiquiatría - entendida en muchas ocasiones como una extensión del programa neurológico de la escuela cajaliana -, el único caso que ha merecido la atención de los historiadores de la medicina ha sido la influencia sobre la Salud Pública (Rodríguez Ocaña, 2010). Ningún interés han levantado, hasta el momento, los viajes de los dermatólogos, anestesistas, cirujanos, pediatras o internistas que disfrutaron de las pensiones; en el mejor de los casos, simplemente se citan como parte de algún acercamiento biográfico, presentándose como un elemento casi inocuo sobre los médicos.

Respecto a la cultura de laboratorio, el interés particular de la JAE está fuera de toda duda (Baratas Díaz, 1997; Barona, 2007). Es más, el organigrama de secciones y laboratorios 
que se creó para el organismo estatal parece, a priori, dejar a las disciplinas clínicas sin un espacio - académico y físico - en el que desarrollarse. La estructura de la Junta parecía favorecer un abismo difícil de superar entre ciencias básicas y clínicas. Así, nos planteamos la pregunta de cómo se abrieron camino las especialidades médicas en este mundo en el que la hegemonía de los laboratorios de ciencias básicas era un hecho, y cómo influyó este panorama en la forma de producir ciencia "aplicada" por parte de los clínicos. Como hipótesis de partida, parece factible que el entorno infraestructural de laboratorios creado para la JAE y la larga sombra de Cajal y su ecosistema de laboratorio influyeran a la hora de captar pensionados con una sensibilidad especial hacia la incorporación de estas tecnologías en sus disciplinas.

Con la pediatría como objeto de estudio, abordaremos los cambios profesionales, asistenciales y de espacios que los contactos con el laboratorio extranjero provocaron sobre la especialidad durante el primer tercio del siglo XX. Como fuente primaria principal utilizaremos los expedientes que se conservan en el Archivo de la Junta para Ampliación de Estudios en la Residencia de Estudiantes de Madrid. Comenzaremos con una visión prosopográfica de los pensionados y sus destinos y estudiaremos como subgrupo a los que decidieron visitar laboratorios. Después, pasaremos a analizar, desde el punto de vista biográfico, los casos particulares de Rafael Pérez Montaut, José García del Diestro y Nieves González Barrio.

Para la selección de esta muestra hemos priorizado que estuvieran representadas las diferentes ramas "de laboratorio" (bacteriología, anatomía patológica, parasitología y química) y que la mujer quedara visibilizada como pensionada. Las fuentes elegidas, no obstante, ofrecen muy poca información sobre los médicos puericultores que con "intereses metabólicos" viajaron a otros países en la década de 1930 gracias al programa. Los expedientes de este período conservados en el archivo de la JAE son realmente escuetos.

El de Enrique Jaso Roldán (1904-1993), quien tendrá una gran importancia en la disciplina en los años 60, consta apenas de cuatro folios con sus solicitudes que solo nos dan información sobre su deseo de viajar a Alemania y Austria para estudiar el "metabolismo del agua" en la primera infancia junto a Egon Helmreich (1892-1936), Paul György (1893-1976) y Erwin Schiff (1891-1971). No obstante, el mero interés por esta visión de la fisiopatología del niño y por el trabajo de pediatras bioquímicos, como György, es muy descriptivo al respecto.

El otro caso sería el del catedrático de Valladolid, Evelio Salazar García (1902-1965), que contaba con el apoyo de un contacto clave para la Junta y para la investigación biomédica española del momento como Pio del Río Hortega (1882-1945). Su expediente, a pesar de ser más extenso - diecisiete folios - termina muy pronto. Sabemos que en 1933 estaba en Friburgo de Brisgovia, trabajando sobre "metabolismo energético" con Carl Noeggerath (1876-1952) y, gracias a unas anotaciones al margen de su expediente, tenemos constancia de que trabajó previamente con Schiff, Husler y con Hans Rietschell (1878-1970). Por entonces escribía a la Junta para solicitar una ayuda económica - solo contaba con una "consideración de pensionado" - pero, tras la negativa de la JAE, la correspondencia dejó de fluir. 
La década de los años 30, pues, quedaría poco representada. Para paliarlo, hemos añadido un caso ajeno a la JAE, el de Guillermo Arce Alonso (1901-1970), y que no sólo muestra la relación entre el viaje científico y el laboratorio en estos años, sino que revela la importancia de ampliar la visión y acercarse a otros círculos de intelectuales para valorar este problema en conjunto.

Por quedar fuera del movimiento específico en torno al laboratorio, este proceso de selección obliga a dejar a un lado biografías tan interesantes como la de Rafael García-Duarte y Salcedo (1894-1936). Convertido en un gran renovador de la pediatría académica de su época, disfrutó de una pensión de la Junta para viajar a París, donde trabajó junto a Antoine Marfan (1858-1942) y Adolphe Pinard (1844-1934). Hemos de decir, no obstante, que, como la mayoría de pediatras pensionados que viajaron hasta París, tuvo contacto con el Instituto Pasteur y que, en el programa pediátrico-social que desarrolló a su vuelta en España, el laboratorio tuvo una presencia notable (Rodríguez Ocaña, García-Duarte Ros, 1984).

\section{Destino: laboratorio}

Pero ¿qué es lo que hace que un pediatra elija una estancia en un laboratorio de investigación en lugar de - o como complemento de - un servicio hospitalario? El perfil de los becados estuvo desde un principio muy sesgado por las prioridades investigadoras de la JAE. Consecuentemente, entre los elegidos abundaron pediatras con unas claras inclinaciones hacia el laboratorio. Si echamos un vistazo al conjunto de pensionados (Tabla 1), de los catorce, nueve habían tenido ya un contacto directo con un laboratorio antes de sus viajes al extranjero y, de estos, cuatro contaban con el apadrinamiento directo de un científico "de laboratorio" relacionado con la propia Junta. En concreto, veremos cómo el círculo del hematólogo y parasitólogo italo-español, Gustavo Pittaluga Fattorini (1856-1976), fue propicio para producir vocaciones de laboratorio entre los pediatras.

Tabla 1: Pensionados de la JAE para ampliación de estudios o investigaciones en Pediatría (1907-1936)

\begin{tabular}{|c|c|c|c|c|c|}
\hline Año & Pensionado & $\begin{array}{l}\text { Contacto previo con otros } \\
\text { laboratorios }\end{array}$ & Recomendación & País & Tema \\
\hline 1910 & \multirow{2}{*}{$\begin{array}{l}\text { Rafael Pérez } \\
\text { Montaut } \\
(1884-1940)\end{array}$} & \multirow{2}{*}{$\begin{array}{l}\text { Alumno interno en } \\
\text { la cátedra de Higiene } \\
\text { y Bacteriología de la } \\
\text { Facultad de Medicina de la } \\
\text { Universidad de Madrid }\end{array}$} & \multirow[t]{2}{*}{-} & $\begin{array}{l}\text { Francia } \\
\text { Alemania }\end{array}$ & $\begin{array}{l}\text { Análisis bacteriológicos, } \\
\text { analíticos e histológicos } \\
\text { en relación con la clínica }\end{array}$ \\
\hline 1912 & & & & Alemania & $\begin{array}{l}\text { Anatomía patológica } \\
\text { del timo }\end{array}$ \\
\hline 1913 & $\begin{array}{l}\text { José García del } \\
\text { Diestro } \\
(1882-1935)\end{array}$ & $\begin{array}{l}\text { Estancia en el Instituto } \\
\text { Pasteur de París } \\
\text { Alumno de Parasitología } \\
\text { del laboratorio de Gustavo } \\
\text { Pittaluga }\end{array}$ & Pittaluga & $\begin{array}{l}\text { Italia, Francia, } \\
\text { Túnez y Argel }\end{array}$ & $\begin{array}{l}\text { Kala-Azar infantil y } \\
\text { parásitos del género } \\
\text { Leishmania }\end{array}$ \\
\hline 1920 & $\begin{array}{l}\text { Rafael García- } \\
\text { Duarte y } \\
\text { Salcedo } \\
(1894-1936)\end{array}$ & No & - & Francia & Pediatría \\
\hline
\end{tabular}




\begin{tabular}{|c|c|c|c|c|c|}
\hline Año & Pensionado & $\begin{array}{l}\text { Contacto previo con otros } \\
\text { laboratorios }\end{array}$ & Recomendación & País & Tema \\
\hline 1921 & $\begin{array}{l}\text { Nieves González } \\
\text { Barrio } \\
\text { (1894-c. 1961) }\end{array}$ & $\begin{array}{l}\text { Auxiliar honorario en la } \\
\text { Cátedra de Parasitología } \\
\text { y Patología Tropical de } \\
\text { la Facultad de Medicina } \\
\text { de la Universidad Central } \\
\text { (Pittaluga). } \\
\text { - Instituto Nacional de } \\
\text { Higiene de Alfonso XIII } \\
\text { - Laboratorio Ibys }\end{array}$ & Pittaluga & $\begin{array}{l}\text { Estados } \\
\text { Unidos }\end{array}$ & Higiene infantil \\
\hline 1922 & $\begin{array}{l}\text { Enrique } \\
\text { Nogueras } \\
\text { Corona } \\
(1882-1925)\end{array}$ & & Pittaluga & $\begin{array}{l}\text { Francia y } \\
\text { Alemania }\end{array}$ & $\begin{array}{l}\text { Nutrición del niño de } \\
\text { pecho y funcionamiento, } \\
\text { eficacia y orientación de } \\
\text { las obras de protección } \\
\text { infantil. }\end{array}$ \\
\hline 1924 & $\begin{array}{l}\text { Agapito } \\
\text { Argüelles Terán } \\
(i-1957)\end{array}$ & $\begin{array}{l}\text { Experiencia en investigación } \\
\text { fisiológica }\end{array}$ & - & Suiza & $\begin{array}{l}\text { Instituciones de } \\
\text { puericultura y } \\
\text { maternología }\end{array}$ \\
\hline 1926 & $\begin{array}{l}\text { Miguel Torelló } \\
\text { Cendra } \\
(1899-1936)\end{array}$ & $\begin{array}{l}\text { Experiencia en investigación } \\
\text { bacteriológica }\end{array}$ & - & Francia & $\begin{array}{l}\text { Atrepsia, cólera, } \\
\text { pielitis, tuberculosis y } \\
\text { organización. }\end{array}$ \\
\hline 1927 & $\begin{array}{l}\text { Tomás Sala } \\
\text { Sánchez } \\
(1904-1969)\end{array}$ & No & - & Alemania & $\begin{array}{l}\text { Nutrición y trastornos } \\
\text { nutritivos del lactante, } \\
\text { raquitismo, espasmofilia } \\
\text { y métodos de lactancia } \\
\text { de prematuros y "débiles } \\
\text { congénitos". } \\
\text { Escorbuto y tosferina. } \\
\text { Reacción de Pirquet. }\end{array}$ \\
\hline 1927 & $\begin{array}{l}\text { Luis Navarro } \\
\text { Molina }\end{array}$ & $\begin{array}{l}\text { Formación previa en } \\
\text { bacteriología. }\end{array}$ & - & Francia & Pediatría \\
\hline 1931 & $\begin{array}{l}\text { Antonio } \\
\text { Delgado Roses }\end{array}$ & No & - & $\begin{array}{l}\text { Alemania, } \\
\text { Suiza, Francia }\end{array}$ & $\begin{array}{l}\text { Alimentación del } \\
\text { lactante }\end{array}$ \\
\hline 1933 & $\begin{array}{l}\text { Evelio Salazar } \\
\text { García } \\
(1902-1965)\end{array}$ & $\begin{array}{l}\text { Manejaba técnicas } \\
\text { bacteriológicas y } \\
\text { hematológicas antes de su } \\
\text { pensión }\end{array}$ & $\begin{array}{l}\text { Pío del Río } \\
\text { Hortega }\end{array}$ & Alemania & Metabolismo energético \\
\hline 1934 & $\begin{array}{l}\text { Gaspar } \\
\text { Zaragoza } \\
\text { Fernández }\end{array}$ & $\begin{array}{l}\text { Había estudiado análisis } \\
\text { químico y química biológica }\end{array}$ & $\begin{array}{l}\text { Hipólito } \\
\text { Rodríguez Pinilla }\end{array}$ & Alemania & Pediatría \\
\hline 1935 & $\begin{array}{l}\text { Enrique Jaso } \\
\text { Roldán } \\
\text { (1904-1993) }\end{array}$ & $\begin{array}{l}\text { Encargado de la fisiología } \\
\text { en la Escuela de Puericultura } \\
\text { de Madrid. En su tesis, } \\
\text { estudio de metabolismo de } \\
\text { carbohidratos (Círculo de } \\
\text { Nóvoa Santos) }\end{array}$ & & $\begin{array}{l}\text { Alemania } \\
\text { Austria }\end{array}$ & $\begin{array}{l}\text { Metabolismo del agua } \\
\text { en la infancia }\end{array}$ \\
\hline 1936 & $\begin{array}{l}\text { Gumersindo } \\
\text { Fontán } \\
\text { Maquieira } \\
\text { (1907-1968) } \\
\end{array}$ & & & Alemania & $\begin{array}{l}\text { Trastornos nutritivos del } \\
\text { lactante }\end{array}$ \\
\hline
\end{tabular}

Fuente: elaboración propia a partir de los expedientes conservados en el Archivo de la JAE.

La elección de los laboratorios y de los países a los que enviar a los pensionados respondió a una serie de variables generales y a otras de carácter más personal que intentaremos 
diseccionar a continuación. En un trabajo de 1997, Baratas Díaz describió cuatro rasgos comportamentales de los pensionados para ciencias biomédicas a la hora de elegir país de destino: (1) un interés general - tendencia secular - por Alemania, seguido muy de cerca por Francia, (2) un desplazamiento hacia Suiza durante la Primera Guerra Mundial, debido a su condición de país no beligerante; (3) la progresiva consolidación de Austria como país de destino, y (4) una diferencia de los países elegidos dependiendo del período de la Junta o de la disciplina que se estudie (Baratas Díaz, 1997). Nuestra muestra corrobora estas tendencias para el grupo de los pediatras: el país preferido fue Alemania ( 9 de 15 pensiones), seguida de Francia (7 de 15). Después, se enviaron pensionados de forma puntual a otros países, donde ya influyeron otra serie de variables personales. Entre ellas destacó sobre todas las influencias de los mentores. Uno de los pediatras, guiado por Pittaluga, viajó hasta Italia, un país poco apreciado por el general de las ciencias biomédicas, y otra pediatra, por recomendación de Enrique Suñer, viajó a los Estados Unidos a pesar de que la Junta prefería un viaje europeo.

Austria, por su parte, solo aparece como opción para los pediatras durante los últimos años de vida de la Junta; y el contacto con Suiza, aparece también en este último período y sin relación con la guerra. Durante el período de la Primera Guerra Mundial no se concedieron pensiones a los pediatras, así que la geografía del grupo no se vio desplazada hacia el país neutral de forma obligada. Suiza no fue, por tanto, un país "alternativo" para esta comunidad, sino que atrajo realmente la atención de los pediatras españoles. Incluso especialistas ajenos a la esfera de influencia de la JAE y que llevaron a cabo viajes con otro tipo de financiación - como Guillermo Arce Alonso (1901-1970), Ricardo Zariquiey Cenarro (1870-1943) o Josep María Sala Ginabreda (1903-1976) -, se acercaron hasta Suiza sin relación con el período bélico.

De las 15 pensiones otorgadas para el estudio de las enfermedades del niño, 6 se dedicaron a la asimilación de tecnologías de laboratorio. Adaptándonos a la periodización que en su día hizo Gamero Merino (1988), diremos que el interés por el laboratorio extranjero también respondió a cierta distribución cronológica. A pesar de que el número de pensiones concedidas a pediatras se mantuvo constante durante toda la vida de la Junta - con excepción al parón correspondiente a la Gran Guerra -, el interés por el laboratorio tuvo un gran éxito en los años previos a la instauración de la dictadura de Primo de Rivera. Previamente, durante el período de consolidación de la JAE (1910-1913), se concedieron un par de pensiones con el objetivo de formarse en el laboratorio, pero fue después de la guerra cuando aparecen los pensionados por Pittaluga que consolidarán la tendencia. Bajo el régimen primorriverista (1923-1931), se prefirió la visión clínica y, finalmente será durante el período de la Segunda República (1931-1936) cuando se regrese a la perspectiva de laboratorio, al difundirse un interés general por el metabolismo energético del niño.

La intervención de los mentores, sobre todo de Pittaluga, fue determinante no solo para la selección de pensionados, sino para la conducción hacia ciertas tendencias científicas, como esta de laboratorio. Además, estos contribuyeron a la elaboración de una geografía científica concreta para el grupo de pediatras españoles, incluyéndolos en una red nacional e internacional y estableciendo un diálogo que trascendió en forma de una interrelación dinámica, no solo centro-periferia, sino, como veremos, entre países de la periferia. 


\section{Bacteriología y anatomía patológica: los viajes de Rafael Pérez Montaut}

El primero en lograr el apoyo de la Junta fue el malagueño Rafael Pérez Montaut (18841940) (Figura 1), un médico general con una inclinación particular hacia la patología de la infancia. Su interés por el laboratorio venía muy remarcado en su petición de 1910, de lo que se puede deducir que lo entendía como un valor añadido a su currículum. Solicitaba específicamente viajar al extranjero para aprender técnicas de laboratorio, bacteriología y anatomía patológica y aplicarlos específicamente a las enfermedades de los niños. Mostraba ante la Junta un interés especial por visitar el Instituto Pasteur de París y por completar su formación en Berlín (Pérez Montaut, 10 mar. 1910). Su interés por el laboratorio había sido precoz. Había sido alumno interno en el Laboratorio de Higiene y Bacteriología de la Facultad de Medicina de Madrid y su tesis doctoral se había centrado en el análisis de la orina de los leprosos (Pérez Montaut, 1911). De hecho, en aquel momento estaba trabajando sobre la etiología microbiana de los chancros venéreos.

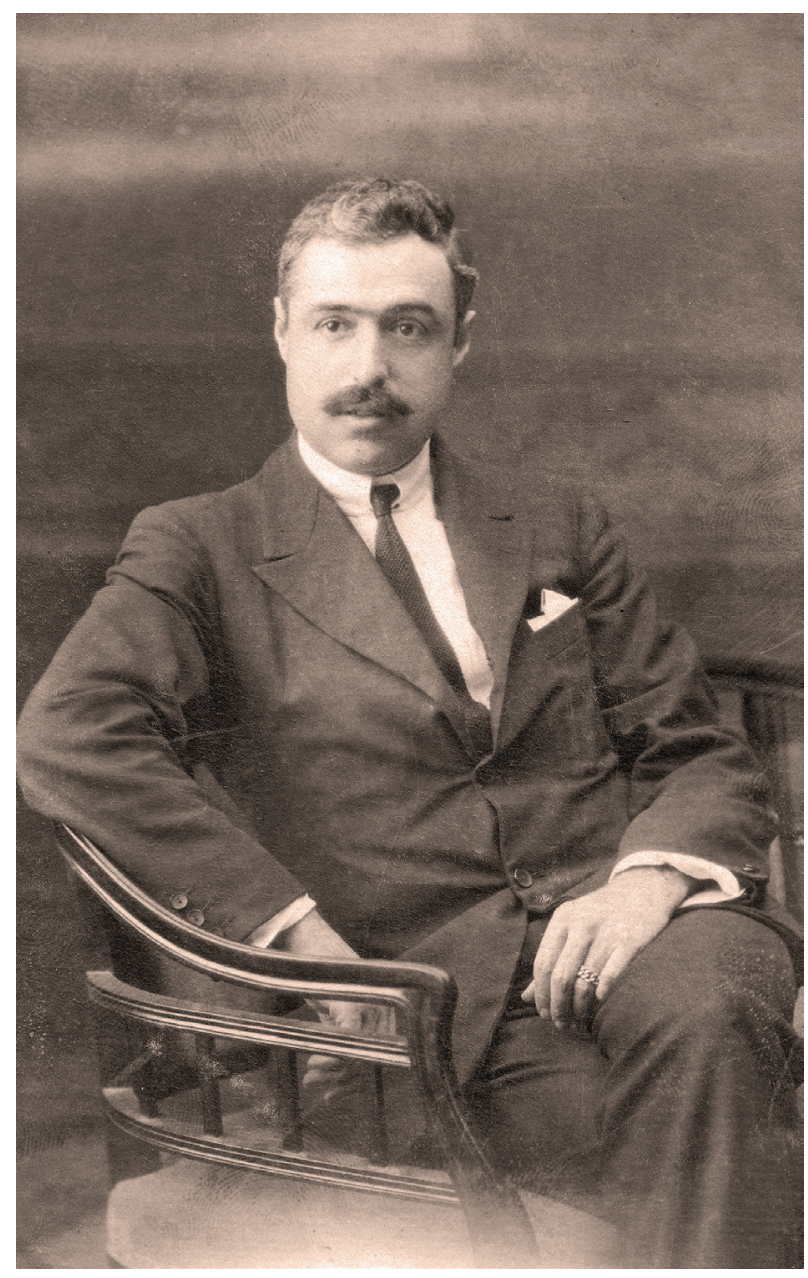

Figura 1: Retrato de Rafael Pérez-Montaut, c.1920

(Photo Hall, Málaga, cortesía de Marisa Pérez-Montaut Salvago) 
Su pensión fue concedida y los destinos respetados. El período que disfrutó en París lo dedicó a aprender análisis clínicos en el Pasteur. Allí elaboró un cuaderno explicando las diferentes técnicas de laboratorio que iba aprendiendo y lo envió, a modo de memoria, a la directiva de la Junta (Pérez Montaut, c.1910). Se adiestró en la seroconversión de la fiebre tifoidea, en el estudio de la resistencia globular en medio hipotónico, en la práctica de hemocultivos, en el examen de la sangre en seco, en el análisis del líquido cefalorraquídeo y en la observación del sedimento urinario. Su interés por la aplicación clínica de estas técnicas hizo que aprovechara la estancia para conocer el Hospital des Enfants Malades de la capital francesa. En su cuaderno de laboratorio recogió los casos en que las técnicas eran útiles para la patología del niño.

Una vez trasladado a Berlín, trabajó junto a Albert Dietrich (1873-1961) en el Departamento de Anatomía Patológica y Bacteriología del Krankenhaus CharlottenburgWestend. Tutelado por Dietrich, Pérez Montaut se dedicó a estudiar la anatomía patológica del timo. Aprovechó la colección de piezas anatomopatológicas del hospital y analizó el órgano en una serie de recién nacidos y lactantes que habían sido etiquetados en su autopsia como "muerte tímica", es decir, una muerte súbita con una hipertrofia tímica como único hallazgo. Estudió así doce timos y consiguió adiestrarse en varias tinciones. Se inició en la básica hematoxilina-eosina y completó el estudio con las tinciones de Giemsa y de verde de metileno, que le permitían observar las células eosinofílicas y las "del plasma" respetivamente (Pérez Montaut, 1912).

Sabemos que el propio Cajal hacía un seguimiento estrecho de algunos de los trabajos de laboratorio de los pensionados. Pérez Montaut, por ejemplo, le envió desde Alemania su cuaderno y todas sus preparaciones anatomopatológicas. Aunque las preparaciones se han perdido, el cuaderno se conserva en el archivo de la JAE. El visto bueno del Nobel - que vio en el joven médico "aplicación y buen conocimiento del asunto" ${ }^{2}$ - solo fue el inicio de un reconocimiento de calidad que pronto llegaría desde los círculos internacionales. El trabajo fue publicado al año siguiente en una revista alemana de anatomía patológica (Pérez Montaut, 1913) y sus conclusiones se reportaron en una importante cantidad de trabajos alemanes y, en menor medida, estadounidenses. Por hablar solo de los libros, aparece citado en el tratado sobre la cirugía del tórax del americano Benjamin M. Ricketts (1958-1926) (Ricketts, 1918) e incluso en el difundido manual de pediatría de Finkelstein (Finkelstein, 1921).

A su regreso a España, la actividad de Pérez Montaut fue esencialmente clínica y no tenemos constancia de ningún trabajo de investigación que firmara después de la pensión. A falta de un estudio en profundidad sobre la introducción de las técnicas de laboratorio en el Hospital Civil y Provincial de Málaga - establecimiento donde trabajó y llegó a ser director durante el período de la República -, no tenemos datos suficientes sobre el proceso de traslación a la clínica de lo aprendido en sus viajes por Europa. Además, las características de la pediatría en estas fechas tan tempranas, vinculada aún en la práctica a la medicina general, hacen muy difícil analizar esta repercusión en la disciplina de forma aislada. 


\section{Un padrino "de laboratorio"}

El siguiente en recibir una pensión - ya en 1913 -, fue José García del Diestro (1882-1935) que, a diferencia de Pérez Montaut, tenía una dedicación completa a las enfermedades de la infancia. En el momento de solicitar la ayuda a la Junta, era médico jefe de las consultas para niños del Real Dispensario Antituberculoso Príncipe Alfonso de Madrid y profesor auxiliar en el llamado Dispensario de enfermedades de la infancia. En paralelo a estas tareas, su relación con el laboratorio era ya un rasgo fundamental de su labor diaria. Al igual que Montaut, había estado catorce meses en el Instituto Pasteur de París y había combinado su actividad con la asistencia a los hospitales infantiles de la capital francesa. Para completar su formación, estaba por entonces realizando un curso de parasitología en la Facultad de Medicina, lo que le había puesto en contacto con Gustavo Pittaluga (García del Diestro, 15 oct. 1912).

Para comprender bien la pensión de García del Diestro, conviene familiarizarse someramente con la biografía del italiano. Nacido en Florencia, Pittaluga estudió medicina en Roma y, tras doctorarse, viajó hasta España por encargo de la farmacéutica Bisleri, interesada en llevar a cabo un programa de estudios de campo con antipalúdicos (Rodríguez Ocaña, 2013). El círculo de Cajal le recibió con interés y terminó por nacionalizarse y desplegar un programa de investigación muy vinculado a los círculos de la JAE. El Nobel le acogió en su laboratorio e incluso le creó una sección de parasitología en el Instituto Nacional de Higiene de Alfonso XIII. Aparte de una rica actividad privada, su autoridad académica alcanzó su cénit con la consecución de una cátedra de parasitología en la Universidad Central. Sus amplios intereses, le llevaron a desarrollar, no solo un programa de investigación parasitológica, sino ambiciosos proyectos "médico-sociales" de lucha contra las enfermedades infecciosas e investigaciones en el área de la hematología clínica. Por su interés en el tema que nos atañe, destacaremos también su peso en el desarrollo de la política científica y de salud pública de su tiempo (Rodríguez Ocaña, 2010, 2013; Rodríguez Ocaña, Borowy, 2008).

Tras despuntar con sus trabajos sobre la malaria, dedicó su esfuerzo al estudio del embrión de las filarias y a un proyecto de investigación sobre la tripanosomiasis en los territorios coloniales españoles en África (Rodríguez-Ocaña et al., 2003). En 1912, se centró en el estudio de la leishmaniasis. El protozoo había sido hallado en Portugal y, teniendo en cuenta su distribución geográfica conocida, Pittaluga postuló que España sería un nicho ecológico ideal para Leishmania infantum (Fernández Martínez, 1914). Para demostrarlo, invitó a varios médicos españoles, entre los que se encontraba García del Diestro, a que se unieran a su equipo. ${ }^{3}$ De esta manera, creó una red nacional de vigilancia parasitológica y, desde lugares tan remotos como Granada, llegaban para su análisis al instituto de Madrid artrópodos sospechosos de ser los vectores de la enfermedad (Fernández Martínez, 1914).

Con los contactos de Pittaluga no fue difícil la obtención de una ayuda de la JAE para García del Diestro con el objetivo de asimilar las técnicas parasitológicas vigentes en Europa. En este caso, el papel del mentor en la elección de los destinos es evidente. El primer laboratorio que se cita en la solicitud a la Junta es el laboratorio de anatomía comparada de uno de los más importantes contactos de Pittaluga en su país de origen, Giovanni Battista Grassi (1854-1925); le siguen el Instituto de Higiene Colonial en Nápoles; el Laboratorio de Parasitología de la Universidad de Catania (Sicilia); y, finalmente, el laboratorio de Charles 
Nicolle (1866-1936) en Túnez, integrado en el Instituto Pasteur, y donde se había descrito por primera vez el parásito. De hecho, gracias a la colaboración en la lucha antipalúdica, existían unas estrechas relaciones entre los científicos españoles - especialmente el grupo de Pittaluga - y los parasitólogos franceses que desarrollaban sus investigaciones en las colonias del Norte de África (Rodríguez-Ocaña, 2017).

Los tres primeros meses, el pensionado permaneció en Italia. Allí tuvo una intensa actividad en servicios clínicos de pediatría que trabajaban muy en relación con el laboratorio. En Palermo, conoció la actividad diaria del servicio de Rocco Jemma (1866-1949), donde pudo ver varios casos de leishmaniasis, presenciar autopsias, practicar numerosas punciones de bazo y estudiar el cultivo y la enfermedad experimental junto al jefe de servicio (García del Diestro, 1912). Posteriormente, en Catania, conoció a Antonino Longo (1874-1943), que había aislado por primera vez el protozoo en Europa (Farnentani, Farnentani, 2007).

Antes de comenzar sus trabajos en el laboratorio de Nicolle, en Túnez, Pittaluga (1912a, 1912b) había conseguido ya demostrar la presencia de Leishmania en España. Cuando García del Diestro regresó a la Península, eso sí, publicó un extenso artículo junto a su mentor que se convirtió en la referencia para el estudio del parásito en el país (Pittaluga, García del Diestro, Vilá, 1912). La productividad a medio plazo de la pensión de García del Diestro fue, en términos científicos, mucho mayor que la de Pérez Montaut. A diferencia de este último, la estrecha vinculación de García del Diestro con Pittaluga y el hecho de residir en Madrid - hay que recordar que la JAE fue un organismo fundamentalmente centralista - le permitió contar con una infraestructura de laboratorio suficiente - la del Instituto de Higiene Alfonso XIII - para proseguir sus trabajos de investigación y aplicar lo aprendido en el extranjero. En Málaga, ningún laboratorio podía estar a la altura de los erigidos en Madrid a la sombra de la Junta. Es más, García del Diestro coincidió con lo que María Isabel Porras Gallo (1998) llama la "fase de madurez" del Alfonso XIII, que en 1923, podía compararse, en palabras de Cajal, con los mejores laboratorios extranjeros del momento.

Con este espacio y material a su alcance, García del Diestro consiguió publicar el primer caso de leishmaniasis de Madrid. (García del Diestro, 30 sept. 1914). Además, la metodología de laboratorio del Instituto Pasteur de Túnez fue reproducida por otros miembros de la red nacional creada por Pittaluga; y así, por ejemplo, en Granada, el médico Fidel Fernández Martínez se apropió de aquella tecnología gracias al viaje del pensionado y contribuyó a la detección del parásito en su área (Fernández Martínez, 1914).

Hasta 1931, simultáneamente con su actividad en el Alfonso XIII y consulta privada, García del Diestro trabajó como jefe de la Sección de Enfermedades de la Infancia del Instituto Rubio. Allí encontró un completo laboratorio dirigido por José Luis Rodríguez Illera, que precisamente procedía del círculo del Instituto Nacional de Higiene. Desde allí, el ex pensionado continuó con sus investigaciones y, además de seguir con el kala-azar, dedicó varios trabajos a la tuberculosis (García del Diestro, 1919; García del Diestro, Cordero, 1920). Además, comenzó una serie de experimentos sobre el raquitismo, los quistes hidatídicos de pulmón, los "vómitos habituales" e incluso llevó a cabo ensayos clínicos con vacunas y éter en el coqueluche (Sesión..., 1928; Memoria..., 1930).

El laboratorio de Illera ofrecía numerosas técnicas aprovechables para la patología del niño y García del Diestro las supo utilizar en su labor clínica diaria. El hemograma, la 
reacción de Fahranan por la técnica de Lizenniever, la cuantificación de glucosa plasmática por el método de Benedit, la de la colesterina en sangre por el de Grigant y las Reacciones de Wassermann y Meinicke (García del Diestro, 1929) sirvieron al médico puericultor para la traslación de los avances de las "ciencias de laboratorio" a la clínica.

\section{Un laboratorio para la pediatría social}

Otro ejemplo destacable de la intervención de Pittaluga y una muestra del proceso de introducción de la mujer en el panorama intelectual y científico en el contexto institucionista, fue la pediatra Nieves González Barrio (1884-c.1961). En 1914 había sido nombrada ayudante del laboratorio de Pittaluga en la Facultad de Medicina de Madrid y, solo un año después, ya era auxiliar honoraria de la cátedra. Tras doctorarse, en 1917, se unió al equipo del Alfonso XIII y tras un año trabajando como médico rural (González Barrio, 1935), en 1919 estaba totalmente integrada en el equipo; incluso se le nombró personal técnico del Instituto de Biología y Sueroterapia (IBYS) que dirigía Pittaluga. Junto a él, la médico comenzó a desarrollar actividades de investigación en las áreas de bacteriología, hematología y serología (Pittaluga, 9 abr. 1921).

Los primeros trabajos de González Barrio dibujan ya su futuro perfil asistencial e investigador que se sustentó siempre sobre dos pilares: la medicina de laboratorio y la salud comunitaria. Siguiendo los pasos de Pittaluga, la pediatra había publicado algunos trabajos sobre la anatomía patológica del kala-azar infantil y se había acercado al estudio de las células de Kupffer del hígado. Esta visión de laboratorio se completaba con un interés por las aproximaciones comunitarias a la salud. Aprovechando una estancia en Tetuán, por ejemplo, se había interesado por los problemas de la parturienta y el recién nacido y aplicando el punto de vista de la salud colectiva publicó una pequeña monografía sobre patología local (González Barrio, 1918). Los presupuestos sociales de la medicina estadounidense fueron apoderándose progresivamente de sus trabajos y, en este sentido, terminó traduciendo al español el tratado de Richard C. Cabot (1868-1939) sobre la función de las inspectoras a domicilio (Cabot, 1920).

El perfil de González Barrio era el ideal para convertirse en pensionada de la JAE: una médico muy cercana al laboratorio y que desarrollaba su vida profesional alrededor de los círculos de influencia de la Junta. Y no nos referimos solo a Pittaluga. González Barrio estaba plenamente integrada en el ambiente institucionista de la capital y vivía en la llamada "Residencia de Señoritas" que dirigía María de Maeztu (1881-1948). La institución, abiertamente americanófila, había conseguido un sólido vínculo con el International Institute for Girls in Spain, una institución estadounidense creada en la década de 1890 en Boston por la filántropa Alice Gordon Gulick (1847-1903). Gracias a su financiación, un comité de la Residencia de Madrid gestionaba los intercambios científicos y culturales de mujeres entre España y Estados Unidos (Zuloeta, Moreno, 1993; Vázquez Ramil, 2012).

En este ambiente, González Barrio (4 abr. 1921) proyectó viajar a Estados Unidos para seguir sus estudios. Tras un primer intento fallido de trabajar sobre polio con Hideyo Noguchi (1976-1928), sus intereses fueron remodelados por el círculo de Enrique Suñer. A pesar de que, como veremos, no perdió nunca el apoyo de Pittaluga, la figura de Suñer fue determinante 
en sus viajes al extranjero y en su futura carrera profesional. Muy lejos de los presupuestos ideológicos de la JAE - algo que dejará mucho más claro en el escenario que le permitió la dictadura del general Franco - y con una gran animadversión por Pittaluga, Suñer ostentaba por entonces la cátedra de enfermedades de la infancia de Valladolid y se encontraba preparando las oposiciones que pocos meses después le llevarían a la Universidad Central.

La vocación social y colectiva de González Barrio y su relación con Suñer le hicieron interesarse por los milk laboratories americanos, unas organizaciones donde se elaboraban y modificaban leches y fórmulas para la lactancia artificial. La Junta le recomendó viajar primero por Europa (Francia e Inglaterra) (Castillejo, 14 nov. 1922), pero la futura pensionada tenía sus propios consejeros, así como una sorprendente independencia de las decisiones de sus mecenas. ${ }^{4}$ Guiada por la recomendación de Suñer, quería viajar hasta Boston (Suñer Ordóñez, 4 mayo 1921), donde Thomas Morgan Rotch, firme defensor de la prescripción bioquímica de estas leches a modo de fármaco, había creado el primero de estos laboratorios de leche a finales del anterior siglo (Apple, 1987).

Suñer recomendó a González Álvarez que se acercara al centro que dirigía John Price Crozer Griffith (1856-1941), profesor de pediatría de la Universidad de Pensilvania (Suñer Ordóñez, 4 mayo 1921) y cuyo manual para madres y enfermeras (Griffith, 1896) había sido todo un éxito. Como presidente de la comisión de vigilancia de la leche de la Sociedad Pediátrica de Pensilvania, Griffith se había convertido en toda una autoridad en la materia. Los intereses de González Barrio estaban allí completos, pues la comisión giraba alrededor de un laboratorio y contaba con un bacteriólogo, un químico y un veterinario (Shoemaker, 1986).

Las limitaciones que imponían las relaciones de la Residencia de Señoritas con el Instituto Internacional cambiaron el destino de la pensionada. La JAE había decidido no becar a mujeres en EEUU y reducir estos viajes a los que se pudieran financiar mediante el acuerdo con Boston (Bernaldo de Quirós, 2 ago. 1921). Esto hizo que el destino de la pensionada se tuviera que ajustar a unos college establecidos previamente por las estadounidenses. González Barrio fue finalmente enviada a Minnesota. En septiembre de 1921, viajó hasta Winona. Allí, se integró en el College de Saint Teresa y comenzó a investigar como asistente de Leonard G. Rowntree (1883-1959) en la Clínica Mayo. Durante seis meses amplió sus conocimientos de laboratorio, fundamentalmente en bacteriología y en química orgánica (Certificado..., 20 sep. 1921; Certificado... 10 oct. 1921).

Los trabajos de Rowntree - centrados en la fisiopatología del riñón - no cuadraban para nada con sus objetivos. Decidida a lograr su meta, sin comunicarlo a la Junta, se trasladó de nuevo a Nueva York, donde consiguió ser admitida en el Babies Hospital. Una vez instalada, escribió a José Castillejo (1877-1945), el secretario de la JAE, para comunicarle su decisión y rogarle que no rescindiera la ayuda (González Barrio, 6 mayo 1922). De nuevo, la intervención de Pittaluga ante el secretario fue clave para mantener el apoyo a la pensionada (Pittaluga, 17 jun. 1922).

El Babies Hospital gozaba de una gran actualidad en cuanto a hospitales monográficos infantiles. Fundado a finales del siglo XIX, su edificio en aquellos años era una fábrica de ocho plantas en la Avenida Lexington, en el barrio de Manhattan, que acogía ochenta cunas y camas para lactantes y niños de hasta tres años de edad. Su director, el pediatra Luther Emmett Holt (1855-1924), lo había organizado en torno a la medicina de laboratorio; incluso 
había contratado bioquímicos en su plantilla. Aliado con la Fundación Rockefeller, Holt habían conseguido desarrollar, entre otros proyectos, un potente programa de investigación sobre el análisis químico de la leche (Corner, 1964). El objetivo de la pensionada en el Babies quedaba claro.

A pesar del desplante de González Barrio, con el apoyo de Pittaluga y Castillejo, la intelectualidad institucionista siguió dando soporte a su proyecto. Ambos se habían convertido en los más importantes interlocutores entre la JAE y la Fundación Rockefeller (Rodríguez Ocaña, 2000; Barona, Bernabeu-Mestre, 2008), por lo que el Secretario intentó mediar con los americanos para sufragar los gastos de la pensionada (Castillejo, 10 jul. 1922). En paralelo, envió cartas al director general de Sanidad, Manuel Martín Salazar (1854-1936), con el objetivo de convencerle de la utilidad del viaje para los programas de salud pública del país. El político mostró su interés por los trabajos de la pediatra y ofreció incluirla en un nuevo proyecto de centros de maternología y cuidado de la primera infancia que se estaba gestando. La Fundación Rockefeller, por su parte, fue tajante con las condiciones de la ayuda: exigía un puesto oficial fijo para González Barrio que le permitiera dedicarse a tiempo completo a aplicar en las instituciones españolas lo aprendido en América (Newcomb, 31 ago. 1922).

En lo que a política sanitaria se refiere, eran años de cambios y España estaba inmersa en lo que Rodríguez Ocaña ha denominado "etapa de formación de la Salud Pública". La disciplina se estaba actualizando y asimilaba por entonces las novedades de la bacteriología y la inmunología (Rodríguez Ocaña, 1994). En este contexto, Martín Salazar planteó la creación de un centro directivo nacional de lucha contra la mortalidad infantil, destinado a coordinar y financiar las "gotas de leche" y demás dispensarios. Se crearía para González Barrio un puesto de inspectora con el objetivo de importar la figura de la enfermera visitadora desde los Estados Unidos (Martín Salazar, 1 sep. 1922).

Las condiciones del puesto que ofrecía el Estado español, sin embargo, no convencieron a la puericultora. El sueldo ofrecido - entre 5 mil y 6 mil pesetas anuales - y la firma de una exclusividad con el gobierno durante 10 años -, no fueron aceptados. Aunque la cantidad se acercaba a lo asignado a un profesor universitario, no le permitiría practicar la medicina privada, por lo que, finalmente, su sueldo no sería comparable con el resto de colegas, que, en general, compatibilizaban la práctica clínica con la vida académica. Y es que, las experiencias de los pensionados de la JAE en el extranjero tuvieron definitivamente un gran peso en su definición como autoridades expertas a su vuelta a España (Suay-Matallana, 2017). La percepción de esta autoridad por el público general, traducida en forma de reputación médica, debió presentarse como un buen reclamo para una consulta privada. El interés de González Barrio por asegurarse el derecho a la actividad privada post pensión es una buena prueba de que este esquema formaba parte de los intereses de los pensionados cuando se decidían a emprender sus viajes.

El acuerdo, finalmente, no se cerró y el viaje concluyó entonces, tras casi otros seis meses de estancia en la costa este y después de conocer el funcionamiento de las enfermeras visitadoras en Boston, Baltimore, Newbedford, Washington y Filadelfia (González Barrio, 1935). ${ }^{5}$ A su vuelta, González Barrio abrió finalmente su propia consulta privada en Madrid y consiguió integrarse en el Instituto Rubio como profesora encargada del laboratorio. Durante este período, coincidió con García del Diestro, e incluso siguieron trabajando juntos en leishmaniasis 
(García del Diestro, González Barrio, 1920). Sin embargo, terminó desvinculándose del círculo de Pittaluga y cerrando filas alrededor de Suñer. A finales de la década, la encontramos incorporada a la cátedra de la Universidad Central como auxiliar honorario y como encargada del laboratorio de enfermedades de la infancia del Hospital de San Carlos.

Cuando, en 1925, Suñer creó la Escuela Nacional de Puericultura, se convirtió en la encargada del laboratorio y en la responsable de organizar el servicio de enfermeras visitadoras y niñeras (González Barrio, 15 dic. 1935). La implantación de este sistema en España y su libro, Organización y reglamentación del cuerpo de visitadoras (González Barrio, 1930), resultaron la cumbre científica de su viaje a América y de su proceso de apropiación de la puericultura social estadounidense. De hecho, su inspiración fundamental fue el informe sobre el tema, elaborado en 1919 por la Fundación Rockefeller y la National Organization for Public Health Nursing (Bernabeu Mestre, Gascón, 1999).

Conociendo la trayectoria de la pensionada, la presencia del laboratorio y la microbiología se convirtieron en claves para la formación de estas visitadoras. La enseñanza de laboratorio ocupaba durante el primer año de formación cuatro horas semanales, cuando, por ejemplo, asignaturas más "clásicas" como la higiene general solo contaban con tres horas, o la dietética, dos. La nueva visión y el tecnocentrismo de la Fundación Rockefeller, se instauraron en el proyecto. La única iconografía que hemos conservado sobre la formación de estas nuevas profesionales (Figura 2) es muy ilustradora de la importancia del laboratorio en este proyecto de salud comunitaria. Apareció en una entrevista concedida por González Barrio a la revista Blanco y Negro en 1935, por lo que se trata de una iconografía ofrecida a los medios de comunicación por ella misma. Representarse con su bata de laboratorio, en ese espacio en concreto, junto a sus alumnas y sin presencia masculina en el medio de una mesa repleta de instrumental fue toda una declaración de intenciones.

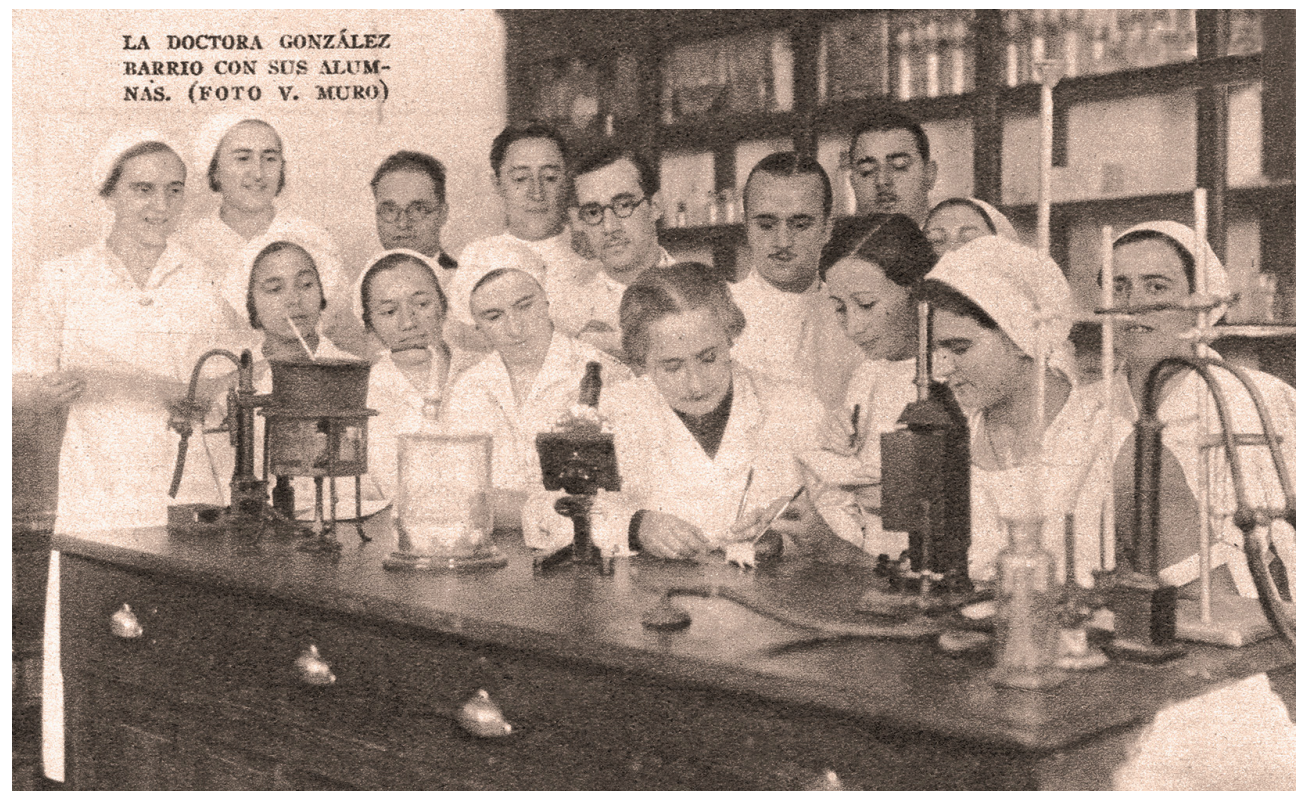

Figura 2: Nieves González Barrio junto a sus alumnas en el laboratorio, c.1930 (Blanco y Negro, 15 dic. 1935, p.161) 
Con el plan a pleno rendimiento, completó su formación internacional viajando en 1930 a Londres y a París. Desconocemos la financiación de estos últimos viajes, pero le permitieron seguir formándose en la aplicación de las técnicas de laboratorio a la investigación pediátrica. En París, por ejemplo, trabajó bajo la dirección de Pierre Nobécourt (1871-1943) y, a su vuelta, por recomendación de éste, realizó la determinación del calcio sanguíneo en un grupo de pacientes del servicio de la Facultad de Medicina de Madrid diagnosticados de "piloroespasmo" (Rodrigo, 1926). En medio de una discusión internacional sobre la etiopatogenia del cuadro, con González Barrio entre sus filas, el laboratorio resultó indispensable para el posicionamiento de Suñer y su equipo.

\section{Vaivenes políticos}

Con raíces en el período anterior, y en paralelo a otra serie de reformas (Rodríguez Ocaña, 2008), durante la Segunda República arrancó definitivamente la Escuela Nacional de Sanidad. Siendo Pittaluga su primer director y con el Instituto Alfonso XIII como parte del corpus infraestructural de origen, el laboratorio (la bacteriología, la serología, la inmunología, la parasitología y la física y la química de la higiene) pasaron a formar una parte muy importante del proyecto (Bernabeu Mestre, 1994). Mientras que la institución de Suñer - la Escuela Nacional de Puericultura - preparaba pediatras y enfermeras especializadas, ésta formaría "oficiales sanitarios". Estos profesionales también tenían competencias en higiene escolar y García del Diestro fue nombrado profesor agregado de esta disciplina. Lo que está claro es que Nieves González ya formaba parte del grupo de Suñer y su nombre ya no aparece en el nuevo proyecto de Pittaluga.

De hecho, los que orbitaban alrededor de Suñer vivieron malos años en el nuevo contexto político. Vehemente siempre en sus discursos, los días antes de la proclamación de la República, el catedrático hizo una dura crítica contra la revuelta estudiantil del 25 de marzo. Su actitud fue suficiente para sufrir una dura represión profesional: a finales de año ya estaba apartado de su cátedra y de la dirección de la Escuela Nacional de Puericultura. González Barrio cayó junto a su mentor (González Barrio, 15 dic. 1935) y el grupo de Pittaluga ocupó el nicho que estos dejaron. El nuevo director de la Escuela Nacional de Puericultura sería García del Diestro: “¡Cuántas facilidades encontraban los recomendados por los 'amigos' de la Institución [Libre de Enseñanza] y qué dificultades los procedentes de otros sectores alejados de ésta! Yo fui testigo personal" - afirmaba Suñer (1938, p.29-30).

Su discípulo, Ciriaco Laguna Serrano (1905-1991), tuvo que recurrir a la Fundación Conde de Cartagena para la subvención un viaje a Viena y a Berlín en 1932 y desconocemos de dónde vino la financiación que recibió otro de ellos, Rafael Ramos Fernández (19071955), que viajó a Francia y a Alemania.

Tras la Guerra Civil, el panorama de los pediatras formados en el mundo del laboratorio a la sombra de la JAE había quedado devastado. Para González Barrio, el golpe del período de la República fue tal, que no conocemos trabajos de investigación ni responsabilidades de laboratorio desde la proclamación del Estado republicano; ni siquiera la restauración de Suñer en su cátedra por las autoridades franquistas devolvió a la puericultora a la escena científica. García del Diestro murió poco antes de comenzar la Guerra, Pérez Montaut no superó la 
posguerra y murió a los 56 años; solo quedaban en activo los más jóvenes: Salazar y Jaso. Además de recuperar la Escuela Nacional de Puericultura, Suñer estuvo muy involucrado en los procesos de depuración, por lo que los poderes quedaban de nuevo bien dibujados y la nueva pediatría, perfilada. Salazar consiguió superar la depuración y siguió como catedrático en Santiago; Enrique Jaso, por el contrario, vivirá la represión de la dictadura. Vinculado durante la Guerra a las actividades puericultoras bajo los mandos del gobierno republicano de Valencia, será apartado de sus cargos y no será restituido hasta 1956.

Pero, para apreciar la importancia de los viajes del primer tercio del siglo XX para el establecimiento de la cultura de laboratorio en la pediatría española y cómo ésta consiguió sobrevivir a la Guerra Civil tenemos que recurrir a un ejemplo alejado de la JAE. A finales de la década de 1920, Guillermo Arce decidió crear un laboratorio para su servicio. El contexto de renovación que vivía por aquellos años el centro hospitalario que le había contratado, la Casa de Salud Valdecilla en Santander, fue muy favorecedor para la integración del laboratorio en los espacios asistenciales. Ya en sus primeros años de funcionamiento, la institución estaba dotada de un buen número de laboratorios dedicados a la clínica y otros con funciones de investigación experimental básica, todos integrados en la docencia (Salmón, García Ballester, Arrizabalaga, 1990). Este escenario, por sí solo, podría explicar la fundación del laboratorio de Arce; sin embargo, su discípulo más avezado, Ernesto Sánchez y Sánchez-Villares (1922-1995), defendió con gran acierto que el detonante definitivo fue un viaje científico por Europa (Sánchez Villares, 1992). Una estancia en Alemania donde trabajó con Finkelstein, Hans Kleinschmidt (1885-1977) o Joseph Husler (1885-1976) y viajes más breves a Suiza y Francia (Sánchez Villares, c.1954) introdujeron el laboratorio en su clínica diaria.

En el servicio de Finkelstein, por ejemplo pudo ver cómo la pediatría, la nutrición y la bacteriología trabajaban en íntima relación; de hecho, los espacios estaban allí preparados para desarrollar un programa de investigación de laboratorio en paralelo al asistencial (Weaver, 2013). Esta distribución de espacios fue adoptada en Valdecilla y consiguió transmitirse en el tiempo superando las cribas de la dura posguerra. Durante la Guerra Civil, Arce prestó servicios en el bando nacional e incluso fue delegado provincial de sanidad de la Falange. Con estos antecedentes, consiguió asentar su proyecto sin problemas políticos y crear una sólida escuela pediátrica que dominaría la región Castellano-Cántabro-AsturLeonesa durante décadas. Una buena muestra de la implantación definitiva del modelo es que, en la década de los 50 - emulando a su maestro- Sánchez-Villares creó un laboratorio propio para la clínica de la Cátedra de Pediatría de la Universidad de Salamanca (Velasco Morgado, Rodríguez-Sánchez, en prensa).

\section{Consideraciones finales}

El análisis del caso de la pediatría arroja cierta luz sobre el problema del desarrollo de las especialidades clínicas en el contexto de la Junta para Ampliación de Estudios. Fruto de este ambiente, y aunque éste no fuera un requisito sine qua non para conceder las ayudas, ciertos perfiles de clínicos, muy cercanos al laboratorio y a las ciencias básicas, encontraron un apoyo por parte de la institución. La labor de Pittaluga en esta criba ha quedado bien 
expuesta para el caso, aunque el estudio de otras especialidades podría discernir si su influencia se limitó a la comunidad pediátrica o también influyó en otras vocaciones clínicas de laboratorio.

El programa de la JAE permitió la formación de un grupo de pediatras con una notable capacidad investigadora de laboratorio. El verdadero problema de la Junta - y esto es aplicable a otras muchas disciplinas -, fue el fomento de la actividad post pensión. Los laboratorios de la institución estaban dedicados a las ciencias básicas, por lo que el único espacio estatal de ciencia en el que los pediatras podían aplicar sus nuevos conocimientos a su vuelta a España era éste. Además, con una JAE extremadamente centralista, los pensionados que vivían lejos de Madrid, como Pérez Montaut, no tuvieron la posibilidad de desarrollar un programa de investigación de calidad y encontraron una vía muerta a su regreso.

La actuación de un agente externo con tanto poder como Suñer hizo que la inversión de la Junta germinara en unos espacios completamente ajenos a ésta: la Facultad de Medicina de la Universidad Central, el Clínico de San Carlos y la Escuela Nacional de Puericultura. De este modo, la presencia del laboratorio se estableció como esencial en la docencia de la pediatría, tanto en los programas de licenciatura, como en los de especialización de médicos puericultores y enfermeras visitadoras.

Las pensiones de la JAE y los viajes internacionales de los pediatras españoles en su conjunto contribuyeron al asentamiento progresivo del laboratorio en la pediatría española. Este proceso sucedió - al menos en los círculos de la élite académica y en los lugares más importantes de formación de especialistas - desde finales de la década de 1920 y parecía implantado con cierta estabilidad en los años de la Segunda República. La llegada del nuevo régimen dictatorial significó el fin del proyecto de la Junta, pero la cultura de viaje era ya un fenómeno más grande que el propio proyecto. Esto permitió que la nueva visión de laboratorio se transmitiera más allá de la Guerra Civil por parte de otros pediatras que, alejados de los ambientes de la JAE, habían mantenido los mismos contactos internacionales de laboratorio y que, sin "manchas políticas", lograron ascender a la élite de la especialidad durante el franquismo.

\section{NOTAS}

\footnotetext{
${ }^{1}$ Al igual que el Grupo de Investigación Step (Science and Technology in the European Periphery", utilizaremos el término "apropiación" con un sentido dinámico, en oposición a una "transmisión" aséptica del conocimiento científico. Entendemos la circulación del conocimiento como un "viaje de ida y vuelta", en el que la propia circulación es la que contribuye a la creación de conocimiento (Gavroglu et al. 2008).

${ }^{2}$ Nota autógrafa de Cajal en el manuscrito de Pérez Montaut (1912).

${ }^{3}$ Además de García del Diestro, trabajaron en el asunto bajo la dirección de Pittaluga: el catalán Manuel Vilá, médico en Tortosa y el granadino Fidel Fernández Martínez (1890-1942) (Fernández Martínez, 1914).

${ }^{4}$ Años después, sin embargo, la propia Nieves González Barrio, en unas declaraciones a la revista Blanco $y$ Negro del diario $A B C$, afirmaba haber visitado en París el Instituto Pasteur y varias instituciones de protección a la infancia antes de viajar a Estados Unidos (González Barrio, 15 dic. 1935).

${ }^{5}$ La Rockefeller, sin embargo, no cejó en su empeño de instaurar su programa de enfermeras de salud pública en España. Esto ya sería en el período de la República, con Pittaluga como presidente de la Escuela Nacional de Sanidad y con Suñer y González Barrio fuera del juego administrativo (Barona, Bernabeu-Mestre, 2008).
} 


\section{REFERENCIAS}

ACKERKNECHT, Erwin H.

Medicine and the Paris Hospital, 1794-1848.

Baltimore: Johns Hopkins University Press. 1967.

ÁLVAREZ PELÁEZ, Raquel.

La genética y la Junta para Ampliación de Estudios e Investigaciones Científicas. Asclepio, v.59, n.2, p.163-180. 2007.

APPLE, Rima D.

Mothers and medicine: a social history of infant feeding, 1890-1950. Madison: University of Wisconsin Press. 1987.

BARATAS DÍAZ, Alfredo.

Neurociencias en la Junta para Ampliación de Estudios. Asclepio, v.59, n.2, p.163-136. 2007.

BARATAS DÍAZ, Alfredo.

Introducción y desarrollo de la biología experimental en España entre 1868 y 1936. Madrid: CSIC. 1997.

BARATAS DÍAZ Luis Alfredo; FERNÁNDEZ PÉREZ, Joaquín.

Becas de ampliación de estudios en biología y ciencias básicas de la medicina en la España del primer tercio del siglo XX. Dynamis, v.13, p.247263. 1993.

BARONA, Josep Lluís.

Los laboratorios de la Junta para Ampliación de Estudios e Investigaciones Científicas (JAE) y la Residencia de Estudiantes (1912-1939). Asclepio, v.59, n.2, p.87-114. 2007.

BARONA, Josep Lluis.

Juan Negrín y la investigación experimental en el laboratorio de fisiología de la Junta para Ampliación de Estudios. Dynamis, v.10, p.255273. 1990.

BARONA, Josep Lluís.; BERNABEU-MESTRE, Josep.

La salud y el Estado: el movimiento sanitario internacional y la administración española (18511945). València: Universitat de València. 2008.

BERNABEU MESTRE, Josep.

El papel de la Escuela Nacional de Sanidad en el desarrollo de la salud pública en España, 19241934. Revista de Sanidad e Higiene Pública, v.68, p.65-89. 1994.

BERNABEU MESTRE, Josep; GASCÓN, Encarna. Historia de la enfermería de salud pública en España (1860-1977). Alicante: Universidad de Alicante. 1999.

BERNALDO DE QUIRÓS, Constancio. Carta a Nieves González Barrio. Archivo de la JAE. 71-666. Expediente de María de las Nieves González Barrio, doc. 9 (Archivo de la Residencia de Estudiantes, Madrid). 2 ago. 1921.
CABOT, Richard C.

Ensayos de medicina social: la función de la inspectora a domicilio. Trad. Nieves González Barrio y prólogo de Gustavo Pittaluga. Madrid: Calpe. 1920.

CASTILLEJO, José.

Carta a Virginia Newcomb. Archivo de la JAE. 71666. Expediente de María de las Nieves González Barrio, doc. 33 (Archivo de la Residencia de Estudiantes, Madrid). 14 nov. 1922.

CASTILLEJO, José.

Carta a Nieves González, Archivo de la JAE. 71666. Expediente de María de las Nieves González Barrio, doc. 22 (Archivo de la Residencia de Estudiantes, Madrid). 10 jul. 1922.

CERTIFICADO...

Certificado del director de la Mayo Foundation, Rochester, Minnesota. Archivo de la JAE, 71666. Expediente de María de las Nieves González Barrio, doc. 14 (Archivo de la Residencia de Estudiantes, Madrid). 10 oct. 1921.

CERTIFICADO...

Certificado del presidente del College of Saint Teresa. Archivo de la JAE, 71-666. Expediente de María de las Nieves González Barrio, doc. 11 (Archivo de la Residencia de Estudiantes, Madrid). 20 sep. 1921.

CORNER, George W.

A history of the Rockefeller Institute, 1901-1953: origins and growth. New York: The Rockefeller Institute Press. 1964.

FARNENTANI, Italo; FARNENTANI, Francesca. Antonino Longo: la scuola di Concetti e la nascita della pediatría a Catania. Minerva Pediatrica, v.59, p.825-838. 2007.

FERNÁNDEZ MARTÍNEZ, Fidel.

Los nuevos protozoos parásitos del mediodía de España. Memorias de la Real Sociedad Española de Historia Natural, v.10, n.4, p.193-265. 1914.

FINKELSTEIN, Heinrich.

Lehrbuch der Säuglingskrankheiten. Berlín: J. Springer. 1921.

GAMERO MERINO, Carmela.

Un modelo europeo de renovación pedagógica: José Castillejo. Madrid: CSIC-Instituto de Estudios Manchegos. 1988.

GARCÍA DEL DIESTRO, José. Enfermedad de Adisson. Revista Iberoamericana de Ciencias Médicas, n.41, p.217-218. 1929.

GARCÍA DEL DIESTRO, José.

Estudio clínico de la tuberculosis ganglio-pulmonar en los niños. Madrid: Calpe. 1919. 
GARCÍA DEL DIESTRO, José.

El primer caso de kala-azar infantil en Madrid (nota previa). Revista Clínica de Madrid, v.6, n.18, p.191-197. 30 sept. 1914.

GARCÍA DEL DIESTRO, José. Carta a Santiago Ramón y Cajal. Archivo de la JAE. 61-181. Expediente de José García del Diestro como pensionado, doc. 1 (Archivo de la Residencia de Estudiantes, Madrid). 15 oct. 1912.

GARCÍA DEL DIESTRO, José.

Algunas consideraciones prácticas sobre el kala azar infantil. Revista Clínica de Madrid. v.19, p.258. 1912.

GARCÍA DEL DIESTRO, José; CORDERO, B. A propósito del empleo terapéutico de la tuberculina por vía intradérmica en la tuberculosis pulmonar de los niños. Archivos Españoles de Pediatría. 1920.

\section{GARCÍA DEL DIESTRO, José; GONZÁLEZ} BARRIO, Nieves.

El kala-azar en Madrid. Archivos Españoles de Pediatría. 1920.

GAVROGLU, Kostas et al.

Science and technology in the European periphery: some historiographical reflections. History of Science, v.46, n.2, p.153-175. 2008.

GONZÁLEZ BARRIO, Nieves. Una sincera confesión de la doctora Nieves González Barrio. Blanco y Negro, p.161-162. 15 dic. 1935.

GONZÁLEZ BARRIO, Nieves. Organización y reglamentación del cuerpo e institución de enfermeras visitadoras y acción cultural de las mismas. Madrid: Sociedad Española de Higiene. 1930.

GONZÁLEZ BARRIO, Nieves.

Carta a José Castillejo. Archivo de la JAE. 71666. Expediente de María de las Nieves González Barrio, doc. 20 (Archivo de la Residencia de Estudiantes, Madrid). 6 mayo 1922.

GONZÁLEZ BARRIO, Nieves.

Solicitud de pensión al presidente de la JAE. Archivo de la JAE. 71-666. Expediente de María de las Nieves González Barrio, doc.3 (Archivo de la Residencia de Estudiantes, Madrid). 4 abr. 1921.

GONZÁLEZ BARRIO, Nieves.

Notas de patología local en Tetuán. Madrid: Imprenta y Librería de Nicolás Moya. 1918.

GRIFFITH, J.P. Crozer. Care of the baby: a manual for mothers and nurses. Filadelfia: W.B. Saunders. 1896.
LÓPEZ PIÑERO, José María.

Ciencia y enfermedad en el siglo XIX. Barcelona: Península. 1985.

LÓPEZ PIÑERO, José María.

Patología y medicina interna. In: Laín Entralgo, Pedro (ed.). Historia universal de la medicina. v.6. Madrid: Salvat. 1974.

MARTÍN SALAZAR, Manuel.

Carta a José Castillejo, Archivo de la JAE. 71-

666. Expediente de María de las Nieves González Barrio, doc.25 (Archivo de la Residencia de Estudiantes, Madrid). 1 sep. 1922.

MEMORIA...

Memoria de los trabajos realizados en el Instituto Rubio durante el curso 1929-1930.

Revista Íbero-Americana de Ciencias Médicas, n.59, p.445-455. 1930.

NEWCOMB, Virginia.

Carta a José Castillejo, Archivo de la JAE. 71-

666. Expediente de María de las Nieves González Barrio, doc. 24 (Archivo de la Residencia de Estudiantes, Madrid). 31 ago. 1922.

PÉREZ MONTAUT, Rafael.

Über Thymustod bei kleinen Kindern. Frankfurter Zeitschrift für Pathologie, v.13, p.249. 1913.

PÉREZ MONTAUT, Rafael.

Contribución al estudio de la anatomía patológica del "Thimo" en casos de muerte repentina por hipertrofia del mismo. Manuscrito inédito. Archivo de la JAE P-44. R121.800

(Archivo de la Residencia de Estudiantes, Madrid). 1912.

PÉREZ MONTAUT, Rafael.

Algo sobre las orinas de los leprosos. Memoria (Doctorado) - Facultad de Medicina, Málaga: [s.n.]. 1911.

PÉREZ MONTAUT, Rafael.

Carta a Santiago Ramón y Cajal. Archivo de la JAE, 114-329. Expediente de Rafael Pérez Montaut, doc.2 (Archivo de la Residencia de Estudiantes, Madrid). 10 mar. 1910.

PÉREZ MONTAUT, Rafael.

Sobre la práctica de algunos análisis en particular. [Manuscrito custodiado en Archivo de la JAE]. (Archivo de la Residencia de Estudiantes, Madrid). c.1910.

PITTALUGA, Gustavo.

Carta a José Castillejo, Archivo de la JAE. 71-

666. Expediente de María de las Nieves González Barrio, doc.21 (Archivo de la Residencia de Estudiantes, Madrid). 17 jun. 1922.

PITTALUGA, Gustavo.

Certificación de méritos de María de las Nieves González Barrio. Archivo de la JAE. 71-666. 
Expediente de María de las Nieves González Barrio, doc.4 (Archivo de la Residencia de Estudiantes, Madrid). 9 abr. 1921.

PITTALUGA, Gustavo. Présence de leishmania infantum sur la côte orientale de la Espagne. Bulletin Mensuel de l'Office International d'Hygiene Publique, v.4, n.2, p.2284. 1912a.

\section{PITTALUGA, Gustavo.}

El kala-azar infantil (esplenomegalia parasitaria de los niños) en la Costa de Levante de España. Medicina de los Niños, v.154, p.189-197. 1912b.

PITTALUGA, Gustavo; GARCÍA DEL DIESTRO, José; VILÁ, Manuel.

Estudios sobre el kala-azar infantil y la leishmania infantum en España. Boletín del Instituto de Higiene de Alfonso XIII, v.19, n.2, p.199-227. 1912.

PORRAS GALLO, María Isabel.

Antecedentes y creación del Instituto de Sueroterapia, Vacunación y Bacteriología de Alfonso XIII. Dynamis, v.18, p.81-105. 1998.

RICKETTS, Benjamin M.

Surgery of the thorax and its viscera: symptoms, diagnosis, indications and treatment. Cincinati: El autor. 1918

\section{RODRIGO, Dámaso.}

Contribución a la patogenia del piloespasmo. Revista Ibero-Americana de Ciencias Médicas, n.3, p.133-143. 1926.

\section{RODRÍGUEZ OCAÑA, Esteban.}

Ocaso de la medicina social en España: el caso de la leptospirosis. Asclepio, v.69, n.2, p.199. 2017.

RODRÍGUEZ OCAÑA, Esteban. Pittaluga Fattorini, Gustavo. In: VVAA. Diccionario Biográfico Español. v.41. Madrid: Academia de la Historia. 2013.

RODRÍGUEZ OCAÑA, Esteban.

La JAE y la consolidación de la salud pública en España. In: Sánchez Ron, José Manuel; García-Velasco, José (ed.). 100 JAE: la Junta para Ampliación de Estudios e Investigaciones Científicas en su centenario. v.1. Madrid: Fundación Francisco Giner de los Ríos [Institución Libre de Enseñanza] y Publicaciones de la Residencia de Estudiantes. p.601-623. 2010.

RODRÍGUEZ OCAÑA, Esteban. La sanidad en la II República Española. In: VVAA. El Centro Secundario de Higiene Rural de Talavera de la Reina: 75 aniversario de una experiencia modernizadora en la sanidad. Talavera de la Reina: Colectivo de Investigación Histórica Arrabal. p.5-12. 2008.
RODRÍGUEZ OCAÑA, Esteban.

La intervención de la Fundación Rockefeller en la creación de la sanidad contemporánea en España. Revista Española de Salud Pública, v.74, p.27-34. 2000.

RODRÍGUEZ OCAÑA, Esteban.

La salud pública en España en el contexto europeo, 1890-1925. Revista de Sanidad e Higiene Públicas, v.68, p.11-27. 1994.

RODRÍGUEZ OCAÑA, Esteban; BOROWY, Iris. Gustavo Pittaluga (1876-1956): science as a weapon for social reform in a time of crisis. In: Iris Borowy; Anne Hardy (ed.). Of medicine and men: biographies and ideas in European social medicine between the world wars. Frankfurt: Peter Lang. p.173-196. 2008.

RODRÍGUEZ OCAÑA, Esteban et al. La acción médico-social contra el paludismo en la España metropolitana y colonial del siglo XX. Madrid: CSIC. 2003.

RODRÍGUEZ OCAÑA, Esteban; GARCÍADUARTE ROS, Olga.

Rafael García-Duarte Salcedo (1894-1936): supuestos cientificosociales de un médico puericultor en la Segunda República española. Dynamis, v.4, 175-197. 1984.

SALMÓN, Fernando; GARCÍA BALLESTER, Luis, ARRIZABALAGA, Jon.

La Casa de Salud Valdecilla: la introducción del hospital contemporáneo en España. Santander: Universidad de Cantabria y Asamblea Regional de Cantabria. 1990.

SÁNCHEZ RON, José Manuel (ed.). 1907-1987: la Junta para Ampliación de Estudios e Investigaciones Científicas 80 años después. Madrid: CSIC. 1987.

SÁNCHEZ RON, José Manuel; GARCÍA

VELASCO, José (Ed.).

100 JAE: La Junta para Ampliación de Estudios e Investigaciones Científicas en su centenario. Madrid: Fundación Francisco Giner de los Ríos [Institución Libre de Enseñanza] y Publicaciones de la Residencia de Estudiantes. 2010.

SÁNCHEZ VILLARES, Ernesto.

Guillermo Arce y la generación de "los pH". Boletín de Pediatría, v.33, p.329-330. 1992.

SÁNCHEZ VILLARES, Ernesto.

Proyecto de hospital infantil. Box 53, Folder 483. Rockefeller Foundation records, field offices.

Paris, RG6, SG 1: Series 2: Post-war; Subseries 01: Postwar. Correspondence (Rockefeller Archive Center, Nueva York). c.1954.

SEIDLER, Eduard.

El desarrollo de la pediatría moderna. In: Laín Entralgo, Pedro (ed.). Historia universal de la 
medicina. t. 6. Positivismo. Madrid: Salvat. p.203-215. 1974.

SESIÓN...

Sesión inaugural del curso 1928-1929 [del Instituto Rubio]. Revista Íbero-Americana de Ciencias Médicas, n.34, p.143-149. 1928.

SHOEMAKER, Susan Turnbull.

The Philadelphia Pediatric Society and its Milk Commission, 1896-1917: as aspect of urban progressive reform. Pennsylvania History, v.53, n.4, p.273-288. 1986.

SIMÕES, Ana; CARNEIRO, Ana; DIOGO, M. Paula.

Travels of learning. Introductory remarks. In: Simões, Ana; Carneiro, Ana; Diogo, M. Paula (ed.). Travels of learning: a geography of science in Europe. Dordrecht: Kluwer. 2003.

STURDY, Steve.

Looking for trouble: medical science and clinical practice in the historiography of modern medicine. Social History of Medicine, v.24, n.3, p.739-757. 2011.

SUAY-MATALLANA, Ignacio.

Entre Alemania y América: José Casares Gil y los viajes científicos en la construcción de la autoridad experta en la España contemporánea. Historia Crítica, v.66, p.25-44. 2017.

SUÑER ORDÓÑEZ, Enrique. Carta a Nieves González Barrio. Archivo de la JAE. 71-666. Expediente de María de las Nieves González Barrio, doc. 5 (Archivo de la Residencia de Estudiantes, Madrid). 4 mayo 1921.
SUÑER, Enrique.

Los intelectuales y la tragedia española. San Sebastian: Editorial Española. 1938.

VÁZQUEZ RAMIL, Raquel.

Mujeres y educación en la España contemporánea:

la Institución Libre de Enseñanza y la Residencia de Señoritas de Madrid. Madrid: Akal. 2012.

VELASCO MORGADO, Raúl.

Pensionados para una ciencia en crisis: la JAE como mecenas de la anatomía macroscópica. Dynamis, v.30, p.287-306. 2010.

VELASCO MORGADO, Raúl; RODRÍGUEZSÁNCHEZ, Juan Antonio.

Una verdadera colección de sellos raros: el pediatra como experto en enfermedades de baja prevalencia a mediados del siglo XX en España. In: Rodríguez-Sánchez, Juan Antonio et al. (ed.). Conocimiento y empoderamiento: las enfermedades raras y el síndrome post-polio (1950-2018). Salamanca: Ediciones Universidad de Salamanca. En prensa.

WEAVER, Lawrence.

Kinderheilkunde and continental connections in child health: the "Glasgow School revisited" again. Journal of the History of Medicine and Allied Sciences, v.68, n.4 p.583-626. 2013.

ZULOETA, Carmen de; MORENO, Alicia.

Ni convento ni college: La Residencia de Señoritas. Madrid: Residencia de Estudiantes; CSIC. 1993.

\section{$\rightarrow \rightarrow \rightarrow<<$}

